\title{
Spontaneous Mammary Carcinomas in Female Dogs: Association between Immunohistochemical Degrees of Neoplasia Aggressiveness and Residual Pyrethroids
}

\author{
Marcia Moleta Colodel ${ }^{1 *}$, Isabelle Ferreira ${ }^{1}$, Vera Maria Villamil Martins ${ }^{2}$, Alaor Aparecido Almeida ${ }^{3}$, \\ Maria Denise Lopes ${ }^{4}$, Noeme Sousa Rocha ${ }^{1}$ \\ ${ }^{1}$ Department of Veterinary Clinics, School of Veterinary Medicine and Animal Science (FMVZ), Paulista State University (UNESP), \\ Botucatu, Brazil \\ ${ }^{2}$ Department of Veterinary Medicine, Center for Agroveterinary Sciences (CAV), State University of Santa Catarina (UDESC), \\ Lages, Brazil \\ ${ }^{3}$ Center for Toxicological Assistance (CEATOX), Botucatu Bioscience Institute (IBB), Botucatu, Brazil \\ ${ }^{4}$ Department of Animal Reproduction and Veterinary Radiology, School of Veterinary Medicine and Animal Science (FMVZ), \\ Paulista State University (UNESP), Botucatu, Brazil \\ Email: *marciamoleta2009@hotmail.com
}

Received August 8, 2012; revised September 20, 2012; accepted September 28, 2012

\begin{abstract}
Of the tumors diagnosed in the female dogs have the highest mammary neoplasias incidence. These neoplasias can be influenced by environmental contaminants. Despite evidence of pyrethroid toxicity, carcinogenic potential has not yet been sufficiently elucidated, there is a need to investigate their involvement in mammary tumor. In previous studies, pyrethroid residues were detected in female dogs with mammary neoplasia, however was not investigate the influence of this insecticide in the genesis and aggressiveness of mammary cancer. This study aimed to investigate possible relations between pyrethroid residues and aggressiveness of mammary carcinoma in female dogs. Fifty selected female dogs were divided into five groups of 10 animals each: the Control group, female dogs without mammary neoplasia; the groups Luminal A, Luminal B, HER-2 Superexpression and Basal were constituted by female dogs that presented inguinal mammary carcinoma classified immunohistochemically. The aggressiveness of carcinomas was evaluated by immunohistochemistry (HER-2, p63, estrogen receptor). Residual concentrations of the pyrethroids from the mammary gland and fat tissue adjacent to it were determined by HPLC. Data were analyzed by Chi-Square test. Of the all animals, six presented residues of pyrethroids in mammary samples and 10 presented it in fat tissue samples. There was no statistical evidence that pyrethroids are involved in mammary carcinoma aggressiveness in female dogs.
\end{abstract}

Keywords: Mammary Tumors; Pyrethroids; Carcinogenesis; Neoplasia Aggressiveness

\section{Introduction}

Spontaneous mammary cancer is the most prevalent neoplasia among both female dogs and women [1,2]. Although, in both species, its occurrence varies with age, geography and breed or ethnicity, the incidence of this cancer is, in general, one in four among non-sterilized female dogs aged more than four years [3,4] and one in nine among women aged 50 to 69 years, according to Canadian Cancer Society [5] and Australian Institute of Health and Welfare \& Australasian Association of Cancer Registries [6]. In Brazil, according to estimates from the National Cancer Institute-INCA [7], the number of new mammary cancer cases in 2010 was 49.240 , with a risk estimated at 49 cases per 100 thousand

${ }^{*}$ Corresponding author. women.

An immunohistochemical panel to characterize the prognosis of breast carcinomas in women is utilized routinely in laboratories of human pathology. In the immunohistochemical classification of Perou et al. [8], breast carcinomas in women were subdivided into Luminal A, Luminal B, HER-2 Superexpression and Basal.

The subtype Luminal A, whose phenotype is positive estrogen receptor (ER) and of negative Human Epidermal growth factor Receptor 2-HER-2, is characterized by presenting less aggressive biological behavior. The Luminal B subtype, whose phenotype is ER positive and HER-2 positive, is characterized by moderate aggressiveness. The HER-2 Superexpression subtype, whose phenotype is ER-negative and HER-2 positive, is characterized by loss of control of cell proliferation, confer- 
ring greater aggressiveness to these tumor types in relation to luminal ones. The Basal subtype, whose phenotype is ER-negative and HER-2 negative, is characterized by greater potential for biological aggressiveness [9-11]. The subtype Basal still expresses the proteins p63 and/or cytokeratin-5 commonly present in the nucleus of progenitor or basal cells of the mammary gland [12].

Given this classification, Gama et al. [12] and Sassi et al. [13] tested an immunohistochemical panel utilized in medicine in relation to female dog mammary carcinomas and concluded that, similar to breast cancer in women, the canine form can be classified based on medical markers predictive of tumoral aggressiveness.

In addition to age and breed factors in dogs - as in ethnicity and age in humans with which these animals may live in close association-lifestyle, diet and environmental factors can contribute to the development of some cases of mammary cancer [14].

Currently, pyrethroids are among the environmental contaminants most utilized in agricultural and forested areas, in domiciles, public environments, in programs of public health and in the control of vectors and ectoparasites of animals, including humans [15]. In dogs, pyrethroids are used extensively against a wide gamut of ectoparasites, in different formulations, including pour-on, spray, collars, solutions, shampoos and sprays [16].

Pyrethroids can be absorbed by mammals through the digestive or respiratory system or cutaneously $[16,17]$. The lipophilic character of pyrethroids favors their rapid access to various tissues such as fat and those of the liver, blood, muscle and brain [18,19].

Some epidemiological data indicate that pyrethroids do not act in human carcinogenesis [20-23]. Nevertheless, other surveys have shown a relation between pyrethroids and leukemia [24], prostate cancer [25] and multiple myeloma [26]. These data signal the existence of sufficient evidence to evaluate, very carefully, the participation of these compounds in the etiology of different types of cancer in humans and well as dogs, since according to Dagli [14] both species can share the same environment and, therefore, the same exposure conditions.

In relation to mammary cancer, the involvement of pyrethroids was studied in the etiology of mammary neoplasias in an oral carcinogenicity assay in SpragueDawley rats that received 1 to $1000 \mathrm{ppm}$ of the pyrethroid fenvalerate in the diet, for two years. Significant increases in mammary tumor incidence on the order of $51 \%, 57 \%, 70 \%, 65 \%$ and $55 \%$ were observed for the doses of 1, 5, 25, 250 and 1000 ppm, respectively, versus $43 \%$ in the non-treated group [27].

But in a prospective cohort epidemiological study that evaluated the risk of mammary cancer and indirect exposure to 50 specific agrotoxins among 30,454 wives of pesticide applicators, no relation was found between the
309 incidences of mammary cancer registered in the states of Iowa and North Carolina between 1993 and 2000 and the exposure to all the combined pesticides, or isolated exposure to pyrethroid insecticides. However, the researchers emphasize the need for new studies due to the small number of observed cases [28].

In light of these data and the inexistence of similar investigations in dogs, Andrade et al. [29] and Bariane and Rocha [30] researched the deposition of pyrethroids in the fat tissue adjacent to malignant mammary neoplasias of nine and 30 female dogs, respectively. Chromatographic analysis of the samples detected the presence of the pyrethroids allethrin, cyhalothrin, cypermethrin, deltamethrin and tetramethrin in 3 [29] and 16 [30] female canine carriers of mammary neoplasias. The important results obtained by these researchers indicate the need to pursue more detailed studies to verify the influence of this insecticide on the genesis and aggressiveness of mammary cancer in female dogs.

Since canine spontaneous mammary neoplasias present various epidemiological, clinical, biochemical and biological characteristics that are similar to those found in humans $[2,14]$ and given that the two species share the same environment [14], new and more detailed studies of female dogs could provide a comparative model to help elucidate the various aspects of breast carcinogenesis in women.

The present study aimed to identify possible relations between residues of pyrethroids and spontaneous mammary carcinoma in female dogs by correlating them with the immunohistochemical aggressiveness degree of the neoplasia.

\section{Materials and Methods}

This study was conducted according to the Ethical Principles in Animal Experimentation and was approved by the Ethics Committee of FMVZ/UNESP/Botucatu/SP, under protocol number $42 / 2009$. The inclusion of the animals was contingent upon authorization by the owners by means of signing terms of free and clear consent, after being informed about the experimental protocol.

At the Small Animal Clinical Surgery Service and Animal Reproduction Service FMVZ/UNESP/Botucatu/SP, 98 female dogs, aged between seven and 12 years, were selected without predilection for breed; they all presented cytopathological diagnosis of carcinoma of the inguinal mammary gland. Also utilized were 10 healthy female dogs that had been sent to the sterilization program at the Animal Reproduction Service of FMVZ/UNESP/Botucatu/SP, and presented negative clinical diagnosis for mammary neoplasia.

After local antisepsis, the mammary gland lesions of the female dogs with neoplasia were aspirated with a disposable needle, $26 \mathrm{G} 1 / 2$, to obtain a preliminary 
characterization of the enlarged masses as malignant neoplasias of mammary origin. The samples obtained were expellet onto histological slides, fixed in methanol p.a. (Merck, Darmstadt, Germany) and stained in MayGrünwald Giemsa for morphological characterization and fixed in ethanol 95\% (Merck, Darmstadt, Germany) for staining by the Papanicolau method in order to evaluate their characteristics of cellular malignancy. Subsequently, they were analyzed under a light microscope (ZEISS-I Model AXIO Imager A1). The cytopathological malignity criteria were those specified by Allen et al. [31] and adopted by the Pathology Service at FMVZ/UNESP/Botucatu/SP.

For the anatomohistopathological analysis one fragment of tumoral mass $\left(1 \mathrm{~cm}^{2}\right)$ was collected from each of the 98 female dogs with mammary neoplasia submitted to partial or radical mastectomy and one inguinal mammary gland was collected from each of the female dogs without a mammary tumor during the elective staining procedure. Each collected fragment was fixed in 10\% buffered formalin, routinely processed for histopathology and stained with Hematoxylin and Eosin (HE) at the Pathology service of FMVZ/UNESP/Botucatu/SP. From each cut the slide quality was verified, the neoplasia was classified and the location was chosen for collection of the cylinders subsequently evaluated by tissue microarray. The reading of the slides was accomplished in a light microscope (ZEISS-I Model AXIO Imager A1) following the criteria of tumor classification according to cellular composition adopted by the World Health Organization [32].

From the cuts stained with HE, the areas of interest for the immunohistochemical study of the samples were marked on the slides and identified in the donor blocks. In the Pathological Anatomy Service at the A.C. Camargo Hospital/Sao Paulo/SP, the areas identified in donor blocks from the 98 female dogs with mammary carcinoma were removed and transferred to two receptor blocks. In each case two cylinders $2 \mathrm{~mm}$ in diameter were removed from two distinct areas of the tumor. In each receptor block were also included samples of non-neoplastic mammary gland as a control and one sample of normal placenta tissue to orient the block. TMAs were constructed by utilizing the Tissue MicroArray Builder 20010.2, Histopathology Ltd, Hungary. After the construction, $3 \mu \mathrm{m}$ sections were cut and attached to positive charged histological slides (Positive charged adhesion slides, Amitel, Brazil), paraffinized and stored at $-20^{\circ} \mathrm{C}$ until their utilization in immunohistochemical reactions. One section from each receptor block was stained in $\mathrm{HE}$ and reviewed to confirm the presence of morphological areas representative of the original lesions.

The samples contained on the TMA slides were sub- mitted to immunohistochemical reaction following the standard protocol in the Investigative Pathology Laboratory and Compared with the Pathology Service at FMVZ/ UNESP/Botucatu/SP, utilizing the antibodies RE $\alpha$ (clone 6F11, dilution 1:25-Novocastra Laboratories, UK), HER2 (polyclonal, dilution 1:2000-Dako, USA) and p63 (4A4, dilution 1:150 —Dako, USA). For this, after being paraffinized and rehydrated, the samples were submitted to antigen retrieval using Citrate $\mathrm{pH} 6.0$ in a microprocessor-controlled Pascal pressure chamber (Dako, EUA) for 30 seconds at $125^{\circ} \mathrm{C}$. Next, the material was incubated with $3 \%$ hydrogen peroxide diluted in methanol, for 30 minutes in a dark chamber, and subsequently washed with Tris EDTA buffer $\mathrm{pH}$ 7.4. In sequence, the samples were incubated with Protein Block (Novocastra Laboratories, Newcastle, England) for 10 minutes, at ambient temperature and washed with Tris EDTA buffer $\mathrm{pH}$ 7.4. Subsequently they were incubated with primary antibodies diluted in IHC diluent solution (Novocastra Laboratories, Newcastle, England) and applied on sections for incubation overnight at $4^{\circ} \mathrm{C}$. To amplify the signal and to reveal a chromogenic solution of liquid 3,3' diaminobenzidin (DAB) (Dako, Carpinteria, USA), a system based on the polymer NovoLink was utilized (Novocastra Laboratories, Newcastle, England). The sections were counterstained with Harris hematoxylin and dehydrated; then the slides were mounted with coverslips and read with the aid of Permount mounting medium.

The slides were read in a light microscope (ZEISS-I Model AXIO Imager A1) following the prior mapping of TMAs and for each marker a semiquantitative gradation was utilized to evaluate the immunohistochemistry results. The RE $\alpha$ colorations were considered positive when nuclear staining was observed in more than $10 \%$ of cells, as established by Schmitt et al. [33]. Staining intensity gradations for HER-2 were established by optical analysis based on a graduated Hercep Test ${ }^{\circledR}$ scoring system (0: negative, $1+$ : negative, $2+$ : slightly positive, $3+$ strongly positive). The results were considered positive when the tissue was classified as $2+$ or $3+$. The p63 colorations were considered positive when there was nuclear staining [34] in more than $10 \%$ of neoplastic cells.

Based on the data obtained from immunohistochemical reactions, were samples from the 50 female dogs were randomly distributed into five groups of 10 animals each. The Control group was formed by female dogs that presented negative clinical and histopathological diagnoses for mammary neoplasia; the group Luminal A was composed of the female dogs that presented mammary carcinoma classified by immunohistochemistry as Luminal A (ER positive, HER-2 negative and p63 negative); the group Luminal B was constituted by bitches that presented mammary carcinoma immunohistochemi- 
cally classified as Luminal B (ER positive, HER-2 positive and p63 negative); the HER-2 Superexpression group formed by female dogs with mammary carcinoma classified by immunohistochemistry as HER-2 Superexpression (ER negative, HER-2 positive and p63 negative); and the Basal group comprised the bitches that presented mammary carcinoma immunohistochemically classified as Basal (ER negative, HER-2 negative and p63 positive). The number of animals in each age group was similar among the five groups; and all the female dogs selected resided in an urban environment, had access to the interior of the owner's residence, were fed commercial ration and homemade food, were never treated with hormone therapy and had never been submitted to topical treatment with pyrethroids for at least 60 days.

For the toxicological exam, $5 \mathrm{~g}$ of neoplastic tissue and $5 \mathrm{~g}$ of normal inguinal mammary tissue were collected during the mastectomy surgical procedure (female dogs with mammary carcinoma) and elective staining (female dogs without any mammary tumor), respectively. Also collected was $5 \mathrm{~g}$ of fat tissue adjacent to the excised mammary gland from all bitches from all groups. The fragments obtained were maintained under refrigeration at the temperature of $-4^{\circ} \mathrm{C}$ until the toxicological analysis performed by High-Performance Liquid Chromatography-HPLC, according to the method described by [35], adapted for the quantitative determination of pyrethroid residue concentrations in samples of mammary and fat tissue. Both tissues from the 50 female dogs selected were processed for extraction of active principles allethrin, cypermethrin, deltamethrin and tetramethrin according to the criteria utilized at the Toxicological Assistance Center (CEATOX) of the Institute of Biosciences/UNESP/Botucatu/SP.

Both the frequency of residues and the association between the presence of pyrethroids in mammary gland and fat tissue in female dogs with mammary carcinoma were evaluated by the Chi-Square test $\left(x^{2}\right)$, for which the data were organized into a contingency table, adopting a significance level of $p \leq 0.05$ [36].

\section{Results}

The staining of mammary carcinoma cells from female dogs in this study by RE $\alpha$ (Figure 1) and p63 (Figure 2) revealed the typical nuclear coloration pattern, while staining by antibody HER-2 was cytoplasmic (Figure 3).

Among the mammary samples from the 50 bitches evaluated in this experiment, 44 did not show pyrethroid residues while six (12\%) presented residues of at least one pyrethroid (Table 1). The $\chi^{2}$ test found no association between the pyrethroid presence in the mammary tissue and carcinoma occurrence in different immunohistochemical degrees of malignancy $(p>0.05)$.

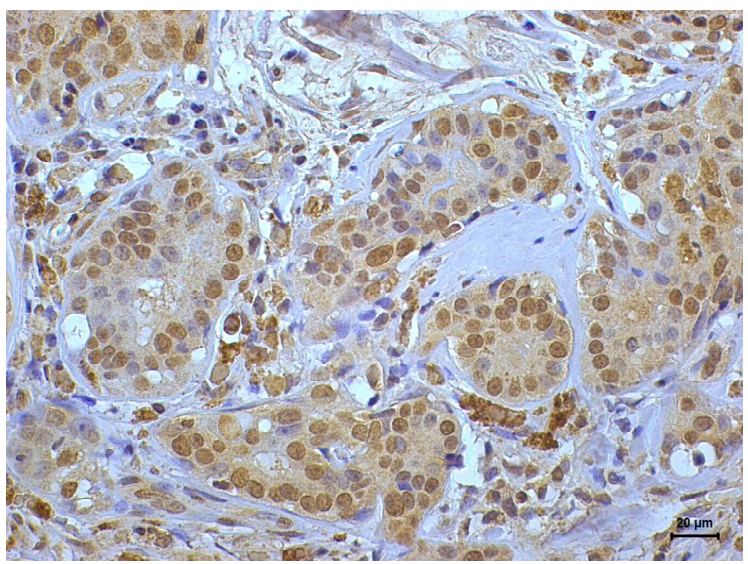

Figure 1. Immunoexpression of estrogen- $\alpha$ receptor in breast carcinoma from a female dog. Nuclear staining in neoplastic cells (immunoreactivity in more than $10 \%$ of neoplastic cells). (DAB, NovoLink, counterstaining with Harris hematoxylin).

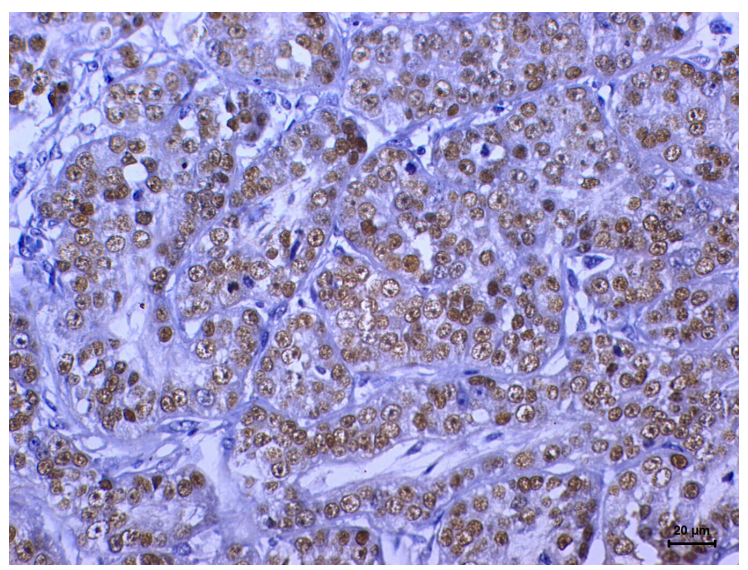

Figure 2. Immunoexpression of p63 in female dog breast carcinoma. Positive nuclear staining in neoplastic cells. (DAB, NovoLink, counterstaining with Harris hematoxylin).

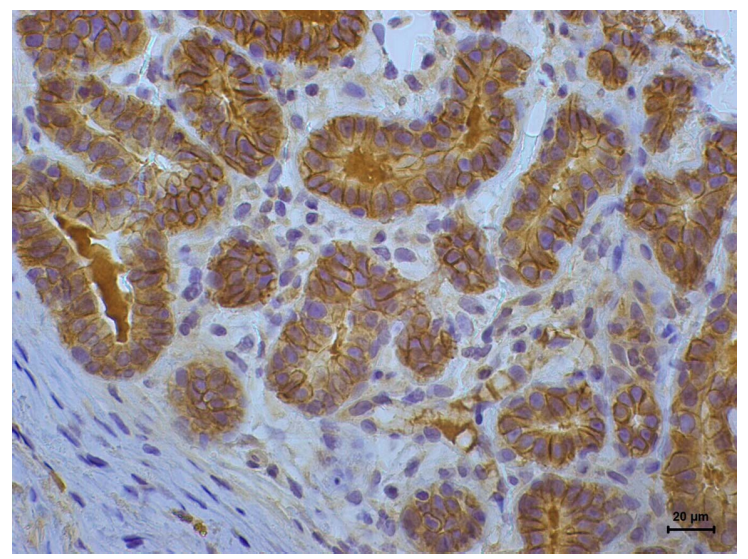

Figure 3. Immunoexpression of HER-2 in female dog mammary carcinoma. Positive staining $3+$ (strongly positive); complete staining of the membrane. (DAB, NovoLink, counterstaining with Harris hematoxylin). 
Pyrethroids were not present in the fat tissue of 40 $(80 \%)$ out of the 50 female dogs in this study (Table 2). The $x^{2}$ test showed no association between pyrethroid presence in fat tissue versus carcinoma occurrence in the different immunohistochemical malignancy degrees ( $p>$ 0.05).

Among the 100 samples analyzed (50 from breast and 50 from fat tissue), although the relation between the residue levels of each of the pyrethroids investigated and immunohistochemical phenotype of carcinomas was not significant $(\mathrm{p}=0.3365)$ by the $x^{2}$ test $\left(\right.$ calculated $x^{2}=$ 13.46), it was observed that the most frequent residue was deltamethrin, which was detected in seven of the female dogs (one from the Control group and two in each of the groups Luminal A, Luminal B and HER-2 Superexpression). The second most commonly found pyrethroid was cypermethrin followed by allethrin (Figure 4).

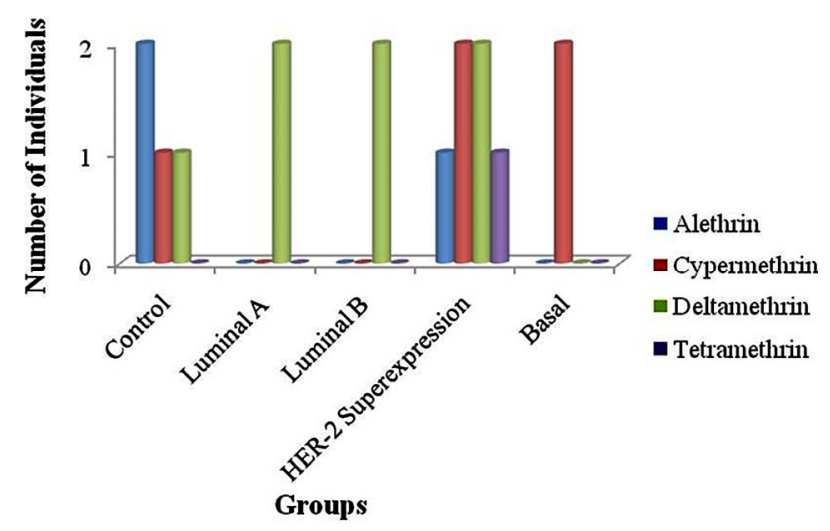

Figure 4. Identification of each pyrethroid investigated in breast and fat tissue adjacent to normal breast (Control group) and of mammary carcinomas (groups Luminal A, Luminal B, HER-2 Superexpression and Basal) in female dogs.

Table 1. Frequencies of residues of pyrethroids in normal breast (Control group) and in breast carcinomas (groups Luminal A, Luminal B, HER-2 Superexpression and Basal) in female dogs.

\begin{tabular}{lccc}
\hline \multirow{2}{*}{ Groups } & \multicolumn{2}{c}{ Pyrethroid Residues } & $\mathrm{n}$ \\
\cline { 2 - 3 } & Absence & Presence & \\
\hline Control & 9 & 1 & 10 \\
Luminal A & 8 & 2 & 10 \\
Luminal B & 8 & 2 & 10 \\
HER-2 Superexpression & 9 & 1 & 10 \\
Basal & 10 & 0 & 10 \\
Total & 44 & 6 & 50 \\
$\mathrm{p}=0.6177$ & & & \\
\hline
\end{tabular}

Calculated $x^{2}=2.652$.
Table 2. Frequencies of residues of pyrethroids in fat tissue adjacent to normal breast (Control group) and in breast carcinomas (groups Luminal A, Luminal B, HER-2 Superexpression and Basal) in female dogs.

\begin{tabular}{lccc}
\hline \multirow{2}{*}{ Groups } & \multicolumn{2}{c}{ Residues of pyrethroids } & \multirow{2}{*}{$\mathrm{n}$} \\
\cline { 2 - 3 } & Absense & Presence & \\
\hline Control & 7 & 3 & 10 \\
Luminal A & 10 & 0 & 10 \\
Luminal B & 9 & 1 & 10 \\
HER-2 Superexpression & 6 & 4 & 10 \\
Basal & 8 & 2 & 10 \\
Total & 40 & 10 & 50 \\
$\mathrm{p}=0.1812$ & & & \\
\hline
\end{tabular}

Calculated $x^{2}=6.25$.

The quantities of each pyrethroid residue investigated (in $\mu \mathrm{g} / \mathrm{g}$ ) were heterogeneously distributed among the groups evaluated and between the mammary and fat tissue samples in the same animal (Table 3).

\section{Discussion}

Evaluating the gene expression of breast neoplasias in women, generally by a technique such as TMA, enables the taxonomic identification of distinct carcinoma subtypes including: Luminal A, Luminal B, HER-2 Superexpression and Basal [8]. These molecular subtypes not only reflect the heterogeneity of mammary carcinomas but also aid in the prognosis of these neoplasias; for example, the subtype Luminal $\mathrm{A}$ is associated with a better therapeutic response, whereas, to the contrary, the Basal subtype is associated with more aggressive behavior and a poorer response to treatment [9-11]. In canine mammary neoplasias, the loss of hormonal receptors in tumoral progression, as well as HER-2 Superexpression in malignancies, have also permitted the molecular classification of carcinomas into subgroups and correlation with the prognosis, similar to human breast cancer $[12,13]$.

This scenario, in which distinct genetic groups are translated by the immunohistochemical phenotypes themselves, is proposed in the present study to identify and quantify residues of pyrethroids in spontaneous mammary carcinoma in female dogs by correlating them with the immunohistochemical aggressiveness profile of these neoplasias. The presence of pyrethroid residues had already been detected in the fat adjacent to neoplastic mammary in female dogs $[29,30]$ however, to the best of our knowledge, assays that seek to evidence pyrethroid residues in the tumoral tissue itself are inexistent in the literature. Furthermore, no study was found that aims to relate these insecticides to aggressiveness immunophenotypes of neoplasia. 
Table 3. Quantification (in $\mu \mathrm{g} / \mathrm{g}$ ) of each pyrethroid investigated in breast and in fat tissue adjacent to normal breast (Control group) and of breast carcinomas (groups Luminal A, Luminal B, Superexpression of HER-2 and Basal) from 50 female dogs.

\begin{tabular}{|c|c|c|c|c|c|c|c|c|c|}
\hline \multicolumn{2}{|c|}{ Control } & \multicolumn{2}{|c|}{ Luminal A } & \multicolumn{2}{|c|}{ Luminal B } & \multicolumn{2}{|c|}{$\begin{array}{c}\text { Superexpression } \\
\text { de HER-2 }\end{array}$} & \multicolumn{2}{|c|}{ Basal } \\
\hline Breast & Fat Tissue & Breast & Fat Tissue & Breast & Fat Tissue & Breast & Fat Tissue & Breast & Fat Tissue \\
\hline nd & nd & nd & nd & nd & nd & nd & nd & nd & nd \\
\hline nd & nd & $0.02 \mathrm{D}$ & nd & nd & nd & nd & nd & nd & $1.99 \mathrm{C}$ \\
\hline nd & nd & nd & nd & nd & nd & nd & $0.20 \mathrm{~A}$ & nd & nd \\
\hline nd & nd & nd & nd & nd & nd & nd & nd & nd & nd \\
\hline $\begin{array}{l}1.23 \mathrm{~A} \\
0.12 \mathrm{D}\end{array}$ & $0.47 \mathrm{~A}$ & nd & nd & $0.17 \mathrm{D}$ & $0.02 \mathrm{D}$ & nd & nd & nd & nd \\
\hline nd & nd & $0.09 \mathrm{D}$ & nd & nd & nd & nd & $0.30 \mathrm{C}$ & nd & nd \\
\hline nd & nd & nd & nd & nd & nd & nd & $0.18 \mathrm{D} 2.25 \mathrm{C}$ & nd & nd \\
\hline nd & $0.93 \mathrm{~A}$ & nd & nd & nd & nd & nd & nd & nd & nd \\
\hline nd & $0.15 \mathrm{C}$ & nd & nd & $0.97 \mathrm{D}$ & nd & $0.30 \mathrm{D}$ & $0.93 \mathrm{~T}$ & nd & nd \\
\hline
\end{tabular}

Detection limit $=0.001 \mu \mathrm{g} / \mathrm{g}, \mathrm{nd}=$ not detected, $\mathrm{A}=$ Allethrin $; \mathrm{C}=$ Cypermethrin $; \mathrm{D}=$ Deltamethrin; $\mathrm{T}=$ Tetramethrin.

In the present experiment, residues of the pyrethroids allethrin, cypermethrin, deltamethrin and tetramethrin were detected not only in some samples of fat tissue adjacent to non-neoplastic and neoplastic mammary but also in non-neoplastic and neoplastic mammary tissue itself; but the presence, type and quantity of the researched pyrethroids were not associated with the immunohistochemical profile of carcinoma aggressiveness.

However, if it is considered that pesticide use is greater in a rural context [15], that in dogs the skin is an important route of contact with pyrethroids [16] and that the residues of this insecticide are eliminated from the fat tissue within an average of one month after a exposure $[19,20]$, the lack of statistical association observed in this study may have occurred because all the female dogs utilized resided in an zone urban and had not received pyrethroid cutaneously for at least 60 days. Therefore, the results may have been underestimated since in this time a majority reduced the degree of exposure to the residues investigated.

On the other hand, given that all the animals in the present research had access to the interior of the residences of their respective owners and received a mixed diet (commercial ration and homemade foods), the presence of pyrethroid residues in fat tissue and/or in mammary tissue demonstrates the influence of the environment on the contamination of these animals since, currently, these pesticides are widely used within and near the human home environment to control insects [15], especially deltamethrin and cypermethrin, the insecticides most detected in the female dogs of the present experiment. In addition, diet may be involved in this context, given that in these animals, the oral route is also an important means of exposure to pyrethroids [19].

In most of the published studies, pesticides are quantified in only one component, namely blood/serum or tissue. In the present study, we opted to analyze the exposure by quantifying the residues of pyrethroids in the mammary and in the fat tissue adjacent to normal or neoplastic mammary gland based on the conceptual premise that the mammary gland, in this case, might be the focus of the insecticide's action while the fat tissue would be the reservoir of the fat-soluble compound, and thus can supply information on the exposure history of the animals submitted to the assay. Furthermore, avail himself, based on the evaluation of the indices of pyrethroids in mammary fat tissue and in the mammary gland itself of the same female dog, it would be an unusual situation and may provide data for comparison of the tissue distribution of this insecticide.

In fact, it was observed that only fourteen bitches in this experiment presented pyrethroid residues in mammary and /or fat tissue, two of which presented residues of more than one of the pyrethroids investigated, but in female dogs that presented residues, heterogeneity was observed in the distribution and probably in the velocity of elimination of these insecticides between the mammary and fat tissue samples in the same animal. This finding reinforces the hypothesis demonstrated by Crawford et al. [18] that there is tissue variation in the metabolism of this insecticide. Nevertheless, the metabolic differences in the pyrethroids between the observed 
mammary and fat tissue, and their clinical significance, need to be investigated more precisely since the detection of pyrethroid residues in neoplastic tissue is an inedited data and the kinetics of the insecticide in this tissue remains unknown.

The International Agency for Research on Cancer (IARC) [37] includes pyrethroids, especially deltamethrin and cypermethrin, in the risk level Group 3, in other words, they are not classified as carcinogenetic in humans, whereas the United States Environmental Protection Agency (US EPA) [38] classifies permethrin and resmethrin as probably cancerigenic to humans (Group 2). Although the pyrethroids are classified, in some situations, as non-cancerigenic, there is substantial evidence for the carcinogenicity of these compounds, both in humans $[20,24,26]$ and in other animals $[39,40]$.

Thus, it is important to emphasize that the same precautions indicated for the use of substances already recognized as cancerigenic must be adopted for the utilization of pyrethroids. But it is difficult to infer that cancer can present a long period of latency and it is related to exposure to a specific pesticide, even though this relationship was not observed in this study. New studies must be encouraged, principally on mammary cancer, an area in which prior publications that sought a link between this particular type of cancer and pyrethroids [27,28] are scarce and contradictory.

\section{Conclusions}

Under the proposed experimental conditions and the sample selected for the present study, it was possible to conclude that there is no statistical evidence that pyrethroids are involved in the aggressiveness of mammary carcinomas in female dogs. Nevertheless, it is necessary to: 1) Study the kinetics of pyrethroids in normal and neoplastic mammary gland and to compare the results with the kinetics of other tissues, principally fat tissue, to evaluate whether the tissue variations may represent some risk for mammary carcinogenesis; 2) Investigate, from the pre-established protocols, whether the concentrations of pyrethroids differ at distinct immunohistochemical degrees of mammary-carcinoma aggressiveness in female dogs.

\section{Acknowledgements}

The authors thank FAPESP (process 2009/52748-3) and CAPES for financial support.

\section{REFERENCES}

[1] H. L. Cameron and W. G. Foster, "Developmental and Lactational Exposure to Dieldrin Alters Mammary Tumorigenesis in Her2/Neu Transgenic Mice," Phos One,
Vol. 4, 2009, pp. 1-8

[2] R. Klopfleisch, D. Lenze, M. Hummel and A. D. Gruber, "Metastatic Canine Mammary Carcinomas Can Be Identified by a Gene Expression Profile That Partly Overlaps with Human Breast Cancer Profiles," BMC Cancer, Vol. 10, 2010, p. 618.

doi:10.1186/1471-2407-10-618

[3] J. W. Fanton and S. J. Withrow, "Canine Mammary Neoplasia: An Overview," California Veterinary Medical Association, Vol. 7, 1981, pp. 12-16.

[4] E. G. Mac Ewen and S. J. Withrow, "Tumors of the Mammary Gland," In: S. J. Withrow and Mac Ewen, Eds., Small Animal Clinical Oncology, Philadelphia, W. B. Saunders Co, 1996, pp. 356-372.

[5] Canadian Cancer Society, Statistics Canada, Provincial/Territorial Cancer Registries, Public Health Agency of Canada, "Canadian Cancer Statistics," 2009.

http://www.cancer.ca/canada-wide/about $\% 20$ cancer/cancer $\%$ 20statistics

[6] Australian Institute of Health and Welfare \& Australasian Association of Cancer Registries 2010, "Cancer in Australia 2010: An Overview," Cancer Series No. 60, Australian Institute of Health and Welfare, Canberra, 2010.

[7] INCA-Instituto Nacional do Câncer. Brasil. Ministério Da Saúde, "Estimativa 2010: Incidence De Cancer No Brasil," Independent Networks Cooperative Association, Rio de Janeiro, 2009.

http://www.inca.gov.br/estimativa/2010/estimativa2009 1201.pdf

[8] C. M. Perou, T. Sorlie, M. B. Eisen, M. Van De Rijn, S. S. Jeffrey, C. A. Rees, J. R. Pollack, D. T. Ross, H. Johnsen, L. A. Akslen, E. Flugel, A. Pergamenchikov, C. Williams, S. X. Zhu, P. E. Lùnning, A. Bùrresen-Dale, P. O. Brown and D. Botstein, "Molecular Portraits of Human Breast Tumours," Nature, Vol. 406, No. 6797, 2000, pp. 747752. doi:10.1038/35021093

[9] T. Sorlie, C. M. Perou, R. Tibshirani, T. Aas, S. Geisler, H. Johnsen, T. Hastie, M. B. Eisen, M. Van De Rijn, S. S. Jeffrey, T. Thorsen, H. Quist, J. C. Matese, P. O. Brown, D. Botstein, P. Eystein Lonning and A. L. Borresen-Dale, "Gene Expression Patterns of Breast Carcinomas Distinguish Tumor Subclasses with Clinical Implications," Proceedings of the National Academy of Sciences, Vol. 98, No. 19, 2001, pp. 10859-10874. doi:10.1073/pnas.191367098

[10] T. Sorlie, "Molecular Portraits of Breast Cancer: Tumour Subtypes as Distinct Disease Entities," European Journal of Cancer \& Clinical Oncology, Vol. 40, No. 18, 2004, pp. 2667-2675.

[11] T. Sorlie, Y. Wang, C. Xiao, H. Johnsen, B. Naume, R. R. Samaha and A. Borresen-Dale, "Distinct Molecular Mechanisms Underlying Clinically Relevant Subtypes of Breast Cancer: Gene Expression Analyses Cross Three Different Platforms," BMC Genomics, Vol. 7, 2006, p. 127. doi:10.1186/1471-2164-7-127

[12] A. Gama, A. Alves, and F. Schmitt, "Identification of Molecular Phenotypes in Canine Mammary Carcinomas with Clinical Implications: Application of the Human Classification," Virchows Archiv, Vol. 453, No. 2, 2008, 
pp. 123-132. doi:10.1007/s00428-008-0644-3

[13] F. Sassi, C. Benazzi, G. Castellani and G. Sarli, "Molecular-Based Tumour Subtypes of Canine Mammary Carcinomas Assessed by Immunohistochemistry," BMC Veterinary Research, Vol. 6, 2010, p. 5. doi:10.1186/1746-6148-6-5

[14] M. L. Z. Dagli, "The Search for Suitable Prognostic Markers for Canine Mammary Tumors: A Promising Outlook," Veterinary Journal, Vol. 177, No. 1, 2008, pp. 3-5. doi:10.1016/j.tvj1.2007.10.015

[15] S. M. Barlow, F. M. Sullivan and J. Lines, "Risk Assessment of the Use of Deltamethrin on Bednets for the Prevention of Malaria," Food and Chemical Toxicology, Vol. 39, No. 5, 2001, pp. 407-422. doi:10.1016/S0278-6915(00)00152-6

[16] A. Anadón, M. R. Martínez-Larrañaga and M. A. Martínez, "Use and Abuse of Pyrethrins and Synthetic Pyrethroids in Veterinary Medicine," Veterinary Journal, Vol. 182, No. 1, 2009, pp. 7-20. doi:10.1016/i.tvil.2008.04.008

[17] D. M. Soderlund, J. M. Clark, L. P. Sheets, L. S. Mullin, V. J. Piccirillo, D. Sargent, J. T. Stevensand and M. L. Weiner, "Mechanisms of Pyrethroid Neurotoxicity: Implications for Cumulative Risk Assessment," Toxicology, Vol. 171, No. 1, 2002, pp. 3-59. doi:10.1016/S0300-483X(01)00569-8

[18] M. J. Crawford, A. Croucher and D. H. Hutson, "Metabolism of Cis- and Trans-Cypermethrin in Rats. Balance and Tissue Retention Study," Journal of Agricultural and Food Chemistry. Vol. 29, No. 1, 1981, pp. 130-135. doi:10.1021/jf00103a033

[19] K. E. Appel and S. Gericke, "Zur Neurotoxizitãt und Toxikokinetik von Pyrethroiden," Bundesgesundheitsblatt, Vol. 36, No. 6, 1993, pp. 219-228.

[20] M. C. R. Alavanja, M. Dosemeci, C. Samanic, J. Lubin, C. F. Lynch, C. Knott, C. Knott, J. Barker, J. Á. Hoppin, D. P. Sandler, J. Coble, K. Thomas and A. Blair, "Pesticides and Lung Cancer Risk in the Agricultural Health Study Cohort," American Journal of Epidemiology, Vol. 160, No. 9, 2004, pp. 876-885. doi:10.1093/aje/kwh290

[21] W. J. Lee, D. P. Sandle, A. Blair, C. Samanic, A. J. Cross, and M. C. R. Alavanja, "Pesticide Use and Colorectal Cancer Risk in the Agricultural Health Study," International Journal of Cancer, Vol. 121, No. 2, 2007, pp. 339-346. doi:10.1002/ijc.22635

[22] G. Andreotti, L. E. Freeman, L. Hou, J. Coble, J. Rusiecki, J. Á. Hoppin, D. T. Silverman, and M. C. Alavanja, "Agricultural Pesticide Use and Pancreatic Cancer Risk in the Agricultural Health Study Cohort," International Journal of Cancer, Vol. 124, No. 10, 2009, pp. 2495-2500. doi:10.1002/ijc. 24185

[23] L. K. Dennis, C. F. Lynch, D. P. Sandler and M. C. R. Alavanja, "Pesticide Use and Cutaneous Melanoma in Pesticide Applicators in the Agricultural Heath Study," Environmental Health Perspectives, Vol. 118, No. 6, 2010, pp. 812-817. doi:10.1289/ehp.0901518

[24] L. M. Brown, A. Blair, R. Gibson, G. D. Everett, D. P. Cantor, L. M. Schuman, L. F. Burmeister, S. F. Van Lier, and F. Dick, "Pesticide Exposures and Other Agricultural
Risk Factors for Leukemia Among Men in Iowa and Minnesota," Cancer Research, Vol. 50, No. 20, 1990, pp. 6585-6591.

[25] M. C. R. Alavanja, C. Samanic, M. Dosemeci, J. Lubin, R. Tarone, C. F. Lynch, C. Knott, K. Thomas, J. Á. Hoppins, J. Barker, J. Coble, D. P. Sandler and A. Blair, "Use of Agricultural Pesticides and Prostate Cancer Risk in the Agricultural Health Study cohort," American Journal of Epidemiology, Vol. 157, No. 9, 2003, pp. 800-814. doi:10.1093/aje/kwg040

[26] J. Á Rusiecki, R. Patel, S. Koutros, L. Beane-Freeman, O. Landgren, M. R. Bonner, J. Coble, J. Lubin, A. Blair, J. Á. Hoppin and M. C. Alavanja, "Cancer incidence Among Pesticide Applicators Exposed to Permethrin in the Agricultural Health Study," Environmental Health Perspectives, Vol. 117, No. 4, 2009, pp. 581-586.

[27] C. M. Parker, D. R. Patterson, G. A. Van Gelder, E. B. Gordon, M. G. Valerio and W. C. Hall, "Chronic Toxicity and Carcinogenicity Evaluation of Fenvalerate in Rats," Journal of Toxicology and Environmental Health, Vol. 13, No. 1, 1984, pp. 83-97. doi:10.1080/15287398409530483

[28] L. S. Engel, D. A. Hill, J. Á. Hoppin, J. H. Lubin, C. F. Lynch, J. Pierce, C. Samanic, D. P. Sandler, A. Blair and M. C. R. Alavanja, "Pesticide Use and Breast Cancer Risk among Farmers' Wives in the Agricultural Health Study," American Journal of Epidemiology, 161, No. 2, 2005, pp. 121-135. doi:10.1093/aje/kwi022

[29] F. H. E. Andrade, F. C. Figueiroa, P. R. O. Bersano, D. Z. Bissacot and N. S. Rocha, "Malignant Mammary Tumor in Female Dogs: Environmental Contaminants," Diagnostic Pathology, Vol. 5, 2010, p. 45. doi:10.1186/1746-1596-5-45

[30] M. H. Bariani and N. S. Rocha, "Residues of Pyrethroids in the Adipose Tissue Adjacent to Spontaneous Mammary Carcinoma in Female Dogs," Revista Cientifica Eletrônica de Medicina Veterinária, Vol. VIII, No. 15, 2010.

[31] S. W. Allen, K. W. Prasse and E. A. Mahaffey, "Cytologic Differentiation of Benign from Malignant Canine Mammary Tumors," Veterinary Pathology, Vol. 23, No. 6, 1986, pp. 649-655.

[32] W. Misdorp, R. W. Else, E. Hellman and T. P. Lipscomb, "Histological Classification of Mammary Tumors of the Dog and the Cat," Vol. 7, Armed Forces Institute of Pathology, Washington DC, 1999, p. 58.

[33] F. C. Schmitt, M. J. Bento and I. Amendoeira, "Estimation of Estrogen Receptor Content in Fine-Needle Aspirates from Breast Cancer Using the Monoclonal Antibody 1D5 and Microwave Oven Processing: Correlation with Paraffin Embedded and Frozen Sections Determinations," Diagnostic Cytopathology, Vol. 13, No. 4, 1995, pp. 347351. doi: $10.1002 / \mathrm{dc} .2840130417$

[34] R. Bhargava, N. N. Esposito and D. J. Dabbs, "Immunohistology of the Breast," In: D. J. Dabbs, Eds., Diagnostic Immunohistochemistry Theranostic and Genomic Applications, WB Saunders Co., Philadelphia, pp. 763-819, 2010.

[35] D. Z. Bissacot and I. Vassilieff, "HPLC Determination of Flumethrin, Deltamethrin, Cypermethrin and Cyhalothrin 
Residues in Milk and Blood of Lactating Dairy Cows," Journal of Analytical Toxicology, Vol. 21, No. 5, 1997, pp. 397-402.

[36] G. W. Snedecor and W. G. Cochran, "Statistical Methods," Iowa State University Press, Ames, 1994.

[37] International Agency for Research Cancer-IARC, "Overall Evaluations of Carcinogenicity to Humans". http://monographs.iarc.fr/ENG/Monographs/vol53/mono 53-10.pdf

[38] United States Environmental Protection Agêncy-US EPA, "Permethrin \& Resmethrin (Pyrethroids). TEACH Chemical Summary. Toxicity and Exposure Assessment for Children's Health".

http://www.epa.gov/teach/chem_summ/pyrethroid_sum- mary.pdf

[39] J. R. P. Cabral, D. Galendo, M. Laval and N. Lyandrat, "Carcinogenicity Studies with Deltamethrin in Mice and Rats," Cancer Letter, Vol. 49, No. 2, 1990, pp. 147-152. doi:10.1016/0304-3835(90)90151-M

[40] Y. Deguchi, T. Yamada, Y. Hirose, H. Nagahori, M. Kushidaj, K. Sumida, T. Sukata, Y. Tomigahara, K. Nishioka, S. Uwagawa, S. Kawamura and Y. Okuno, "Mode of Action Analysis for the Synthetic Pyrethroid Metofluthrin-Induced Rat Liver Tumors: Evidence for Hepatic CYP2B Induction and Hepatocyte Proliferation," Toxicological Sciences, Vol. 108, No. 1, 2009, pp. 69-80. doi:10.1093/toxsci/kfp006 